\title{
Awareness of driving while sleepy and road traffic accidents: prospective study in GAZEL cohort
}

\author{
Hermann Nabi, Alice Guéguen, Mireille Chiron, Sylviane Lafont, Marie Zins, Emmanuel Lagarde
}

\begin{abstract}
Objectives To examine the association between self assessed driving while sleepy and the risk of serious road traffic accidents (RTAs).

Design Prospective cohort study.

Setting France.

Participants 13299 of the 19894 living members of the GAZEL cohort, workers and recent retirees of a French national utility company followed up since 1989.

Main outcome measures Frequency of driving while sleepy in the previous 12 months, reported in 2001; rate ratios for serious RTAs in 2001-3, estimated by using generalised linear Poisson regression models with time dependent covariates. Results The risk of serious RTAs increased proportionally with the frequency of self reported driving while sleepy. After adjustment for sociodemographic characteristics, driving behaviour variables, work conditions, retirement, medical conditions and treatments, depressive symptoms, and sleep disorders, the adjusted rate ratios of serious RTAs for participants who reported driving while sleepy in the previous 12 months "a few times" or "once a month or more often" were 1.5 (95\% confidence interval 1.2 to 2.0$)$ and 2.9 (1.3 to 6.3 ) respectively compared with those who reported not driving while sleepy over the same period. These associations were not explained by any reported sleep disorders.

Conclusions Self assessed driving while sleepy was a powerful predictor of serious RTAs, suggesting that drivers' awareness of their sleepiness while driving is not sufficient to prevent them from having RTAs. Messages on prevention should therefore focus on convincing sleepy drivers to stop driving and sleep before resuming their journey.
\end{abstract}

\section{Introduction}

Sleepiness in drivers is increasingly recognised as an important factor contributing to the burden of traffic related morbidity and mortality ${ }^{1-4}$ but proper assessment of its contribution is lacking. ${ }^{2-4}$ Published estimates of the proportion of road traffic accidents (RTAs) attributable to sleepiness range from 3\% to $33 \%$ according to studies conducted in France, ${ }^{4}$ the United States, ${ }^{56}$ and Australia. ${ }^{7}$ In particular, little is known about the extent to which drivers are able to assess accurately that they are sleepy while driving. ${ }^{5}$

In the 2005 "sleep in America" poll of the National Sleep Foundation, $60 \%$ of America's adults who drive or have a licence reported that they had driven a car or motor vehicle when feeling drowsy or sleepy within the previous year. ${ }^{9}$ A recent survey in France showed that 7 out of 10 French people report periods of sleepiness in the course of the day, and about $6 \%$ admitted to having driven while sleepy at least once during the previous three months. ${ }^{10}$

We did a prospective study in a large cohort of French employees to examine the association between self reported frequency of driving while sleepy over the previous 12 months and the risk of subsequent serious RTAs over the next three years.

\section{Methods \\ Participants}

The participants were current employees or recent retirees of the French national electricity and gas company, who volunteered to participate in a research cohort known as the GAZEL cohort. The GAZEL cohort was established in 1989 and originally included 20624 people working at Electricité De France-Gaz De France (EDF-GDF), comprising men aged 40-50 and women aged 35-50 at baseline. Since 1989, this cohort has been followed up with yearly self administered questionnaires and by data collection from the company's personnel and medical departments. Before inclusion in both the GAZEL cohort and the study on traffic safety, all participants received an information letter describing the main objective of the study and the noncompulsory nature of their participation.

\section{Materials}

We collected data on sleepiness and other driving behaviours in 2001 by using a self administered driving behaviour and road safety questionnaire. We collected data on incident accidents in 2001-3 from the yearly self administered annual GAZEL cohort questionnaire. Finally, when an accident was reported in the GAZEL cohort questionnaire, we sent participants a complementary accident form with 31 questions about the circumstances, the injuries, the reasons for the accident, and the responsibility of the driver.

\section{Data from the GAZEL cohort database}

We recorded sociodemographic and medical data, including self reported sleep disorders (treated or not) and alcohol consumption, ${ }^{11}$ each year in 2001-3 from the GAZEL cohort questionnaire. We also added questions on mobility and accidents in the previous year to the questionnaire in this period. We asked drivers how many kilometres they drove a four wheeled or two wheeled vehicle in the previous 12 months. We also asked the participants to report whether in the previous 12 months they had been involved in one or more serious traffic accidents, defined as an accident that required at least a medical consultation. In the January 2002 questionnaire, we also asked participants to record the date of reported accidents. This 
enabled us to exclude accidents that occurred before the completion of the 2001 driving behaviour and road safety questionnaire.

\section{Driving behaviour and road safety questionnaire}

In 2001, we mailed the driving behaviour and road safety questionnaire to the 19894 living members of the GAZEL cohort. ${ }^{11}$ We assessed driving while sleepy with the question, "In the 12 past months, have you ever driven while sleepy?" $(1=$ never, $2=\mathrm{a}$ few times in the year, $3=$ about once a month, $4=$ about once a week, $5=$ more than once a week). We also recorded other potential confounders, including reported drinking and driving, drugs taken for anxiety, depression, another nervous disease, or sleeping problems, and work conditions (overtime work, time constraints, changing work schedules, and night shifts). We asked participants whether they had ever used connections to avoid paying the fine for a traffic violation. We also asked them to report their maximum speed in built-up areas, on rural roads, and on highways. We suspected participants of having a risky behaviour if they reported answering a phone call (with or without a car kit), whatever the driving circumstances, or if they reported not stopping the vehicle before starting a phone call. We coded the type of principal vehicle owned in January 2001 in five categories corresponding to increasing maximum speed. Finally, we took into account the participants' scores for the type A behaviour pattern assessed in 1993 by the Bortner rating scale. ${ }^{12}$

\section{Statistical analysis}

We regrouped the answers to the questions related to frequency of driving while sleepy into three categories (never, a few times in the year, once a month or more often). We fitted univariate logistic regression models to identify factors associated with reporting driving while sleepy, including medical conditions found to be associated with serious RTAs in previous research. ${ }^{13}$ We then included in a multivariate logistic regression model all the factors that were associated with driving while sleepy with a $\mathrm{P}$ value $<20 \%$ in the univariate analysis.

Because the mean and variance of the number of serious RTAs in 2001-3 did not differ in our study, we used generalised linear Poisson regression models ${ }^{14}$ with time dependent covariates to estimate the rate ratios of serious RTAs in 2001-3 associated with reported driving while sleepy in 2001. We used six nested Poisson regression models to test the impact of potential confounders. In model 1 , sleepy driving was the only independent variable. In model 2 , we further adjusted rate ratios for age, sex, occupational category in 2001, and annual mileage (a time dependent covariate). We applied a logarithmic transformation to annual mileage. In model 3, we further adjusted rate ratios for alcohol consumption (time dependent covariate); reported maximum speed in built-up areas, on rural roads, and on highways; risky use of mobile phones; drinking and driving; and fixing of traffic tickets as reported in $2001 .{ }^{11}$ In model 4 , we also included reported sleep disorders (a time dependent covariate); in model 5 , we further adjusted rate ratios for working overtime, time constraints at work, and working night shifts. Finally, in model 6 , we additionally adjusted rate ratios for depression, use of drugs, and treatment of medical conditions (a time dependent covariate). We fitted the same six nested models to the subsample of participants who did not report any sleep disorders or related treatment in the period.

A proportion of the participants who reported RTAs in one of the three GAZEL cohort questionnaires returned the complementary accident form. This allowed us to compare the characteristics of accidents between people who reported driving while sleepy and others. In this complementary analysis, we included RTAs that did not result in injury but because of which a vehicle needed to be towed away, in addition to serious RTAs, in order to achieve a sufficient sample size. We used Levin's method to calculate the population attributable risk for driving while sleepy. ${ }^{15}$

\section{Results}

We received responses to the 2001 driving behaviour and road safety questionnaire from 14226 of the 19894 living members of the GAZEL cohort. We excluded some $(n=26)$ because of discrepancies in data with the general cohort database. We excluded another 326 respondents because they did not drive in 2001 and 200 respondents because their data on variables for driving while sleepy were missing. This left 13674 participants (10 480 men; 3194 women). To the question "in the 12 past months, have you ever driven while sleepy?” 8597 (62.9\%) participants responded never, $4917(36 \%)$ a few times in the year, $104(0.8 \%)$ about once a month, $35(0.3 \%)$ about once a week, and $21(0.2 \%)$ more than once a week. Table 1 shows factors associated with the odds of reporting driving while sleepy as determined by logistic regression analysis.

\section{Serious road traffic accidents in 2001-3}

We excluded a further 375 of the 13674 participants because they did not respond to any of the three GAZEL cohort questionnaires of the years 2001, 2002, and 2003. Among the remaining 13299 participants, 322 reported one serious RTA, eight reported two serious RTAs, and one reported three serious RTAs in 2001-3, ignoring 76 serious RTAs that were reported to have occurred before the completion of the 2001 driving behaviour and road safety questionnaire.

\section{Self reported sleepy driving frequency and serious road traffic accidents}

Table 2 presents results from generalised linear Poisson regression models fitted to estimate the impact of driving while sleepy on the risk of serious RTAs in 2001-3. Compared with participants who reported not driving while sleepy in the previous 12 months, the unadjusted rate ratio in model 1 was $1.6(95 \%$ confidence interval 1.2 to 2.0) for participants who reported having driven while sleepy "a few times in the year" and 3.0 (1.6 to 6.0) for those who reported having done so "once a month or more often." These associations remained largely unchanged when further adjusted for several sets of potential confounders: the corresponding adjusted rate ratios were 1.5 (1.2 to 2.0) and 2.9 (1.3 to 6.3). When we restricted similar analyses to the subsample of participants who did not report any sleep disorders in 2001-3, the association measures were higher, particularly for participants who reported having driven while sleepy about "once a month or more often." These strong associations persisted after further adjustment for potential confounders. We estimated the population attributable risk for driving while sleepy as $19.2 \%$.

\section{Road traffic accident characteristics}

We received 395 complementary accident forms related to traffic accidents in 2001-3. Examination of the 321 accidents in which the participant was driving showed that the participant was driving a car in 238 cases, a utilitarian vehicle in three cases, a two wheeled motorised vehicle in 19, and a bicycle in 23. Restricting the sample to the 260 accidents in a two to four wheeled motorised vehicle showed significant differences in the proportion of participants who reported at least one episode of 
Table 1 Factors associated with reporting of at least one episode of driving while sleepy in 2001: unadjusted and adjusted odds ratios determined by logistic regression analysis $(n=13674)$

\begin{tabular}{|c|c|c|c|}
\hline Variables & No & $\begin{array}{l}\text { Unadjusted odds ratio } \\
(95 \% \text { Cl) }\end{array}$ & $\begin{array}{c}\text { Adjusted odds ratiof } \\
(95 \% \mathrm{Cl})\end{array}$ \\
\hline \multicolumn{4}{|l|}{ Sex $(n=13$ 674): } \\
\hline Female & 3194 & 1 & 1 \\
\hline Male & 10480 & $1.7(1.5 \text { to } 1.8)^{\star \star * \star}$ & $1.3(1.1 \text { to } 1.6)^{\star \star \star \star \star}$ \\
\hline \multicolumn{4}{|c|}{ Occupational category ( $\mathrm{n}=13$ 660): } \\
\hline Unskilled workers & 1330 & 1 & 1 \\
\hline Skilled workers & 7397 & $1.2(1.0 \text { to } 1.3)^{\star \star}$ & $1.1(0.9 \text { to } 1.4)^{\star}$ \\
\hline Managers & 4933 & $2.2(2.0 \text { to } 2.6)^{\star \star \star \star}$ & $1.8(1.5 \text { to } 2.2)^{* * * *}$ \\
\hline \multicolumn{4}{|c|}{ Driving mileage $(\mathrm{km})$ per year $(\mathrm{n}=12163)$ : } \\
\hline$<10000$ & 2785 & 1 & 1 \\
\hline 10000 to 20000 & 5245 & $1.5(1.4 \text { to } 1.7)^{\star \star \star \star}$ & $1.6(1.4 \text { to } 1.8)^{\star \star \star \star}$ \\
\hline$>20000$ & 4133 & $2.5(2.2 \text { to } 2.7)^{\star \star \star \star \star}$ & $2.2(1.9 \text { to } 2.5)^{\star \star \star \star}$ \\
\hline \multicolumn{4}{|l|}{ Year of birth $(n=13674)$ : } \\
\hline $1939-43$ & 5374 & 1 & 1 \\
\hline 1944-8 & 7080 & $1.3(1.2 \text { to } 1.4)^{\star \star \star \star}$ & $1.2(1.0 \text { to } 1.3)^{\star *}$ \\
\hline $1949-53$ & 1220 & $1.0(0.9$ to 1.2$)$ & $1.4(1.1 \text { to } 1.8)^{\star \star \star}$ \\
\hline \multicolumn{4}{|l|}{ Working overtime ( $\mathrm{n}=13$ 672): } \\
\hline Never & 9015 & 1 & 1 \\
\hline Occasionally & 2283 & $1.3(1.1 \text { to } 1.4)^{\star \star \star \star}$ & $1.3(1.0 \text { to } 1.7)^{\star *}$ \\
\hline Often/always & 2374 & $2.4(2.2 \text { to } 2.6)^{\star \star \star \star \star}$ & $1.6(1.2 \text { to } 2.1)^{\star \star \star}$ \\
\hline \multicolumn{4}{|c|}{ Time constraints at work ( $\mathrm{n}=13$ 673): } \\
\hline Never & 9536 & 1 & 1 \\
\hline Occasionally & 2032 & $1.5(1.4 \text { to } 1.7)^{\star \star \star \star \star}$ & $1.1(0.9 \text { to } 1.4)^{\star}$ \\
\hline Often/always & 2105 & $2.4(2.1 \text { to } 2.6)^{\star \star \star \star \star}$ & $1.3(1.0 \text { to } 1.6)^{\star *}$ \\
\hline \multicolumn{4}{|l|}{ Work schedules ( $\mathrm{n}=13$ 673): } \\
\hline Same every day & 11454 & 1 & 1 \\
\hline $\begin{array}{l}\text { Different and fixed by } \\
\text { company }\end{array}$ & 727 & $1.4(1.2 \text { to } 1.7)^{\star \star \star \star}$ & $1.1(0.9$ to 1.4$)$ \\
\hline $\begin{array}{l}\text { Different and fixed by } \\
\text { yourself }\end{array}$ & 1492 & $2.2(1.9 \text { to } 2.4)^{\star \star \star \star}$ & $1.1(0.9$ to 1.3$)$ \\
\hline \multicolumn{4}{|l|}{ Working night shifts $(n=13670)$ : } \\
\hline Never & 12431 & 1 & 1 \\
\hline Occasionally & 1099 & $2.1(1.8 \text { to } 2.3)^{\star \star \star \star}$ & $1.2(1.0 \text { to } 1.4)^{\star *}$ \\
\hline Regularly & 140 & $2.9(2.0 \text { to } 4.0)^{\star \star \star \star}$ & $1.8(1.1 \text { to } 2.9)^{\star \star}$ \\
\hline \multicolumn{4}{|l|}{ Use of drugs ( $n=13512)$ : } \\
\hline No & 8212 & 1 & 1 \\
\hline For anxiety & 2065 & $1.0(0.8$ to 1.1$)$ & $1.1(1.0 \text { to } 1.3)^{\star *}$ \\
\hline For depression & 684 & $1.1(0.9$ to 1.4$)$ & $1.2(1.0 \text { to } 1.5)^{\star \star}$ \\
\hline For other nervous disease & 220 & $1.6(1.1 \text { to } 2.2)^{\star \star \star}$ & $1.5(1.0 \text { to } 2.2)^{\star \star}$ \\
\hline For sleep & 2325 & $1.2(1.1 \text { to } 1.3)^{\star \star \star \star}$ & 1.8 (0.6 to 5.5$)$ \\
\hline \multicolumn{4}{|l|}{ Retirement ( $n=11$ 764): } \\
\hline No & 7311 & 1 & 1 \\
\hline Yes & 4453 & $0.5(0.5 \text { to } 0.6)^{\star \star \star \star}$ & $0.9(0.8$ to 1.4$)$ \\
\hline
\end{tabular}

Depressive symptoms (CES-D) ( $\mathrm{n}=11272)$ :

\begin{tabular}{lccc}
\hline No & 9236 & 1 & 1 \\
\hline Yes & 2036 & $1.5(1.3 \text { to } 1.6)^{\star \star \star \star}$ & $1.5(1.3 \text { to } 1.7)^{\star \star \star \star \star}$ \\
\hline
\end{tabular}

Alcohol consumption§ ( $\mathrm{n}=13$ 674):

\begin{tabular}{|c|c|c|c|}
\hline Non-drinker & 7673 & 1 & 1 \\
\hline Low quantity regular & 888 & $1.1(1.1 \text { to } 1.3)^{\star \star}$ & $0.5(0.2$ to 1.5$)$ \\
\hline Low quantity episodic & 172 & $1.6(1.2 \text { to } 2.3)^{\star * *}$ & $1.4(0.9 \text { to } 2.0)^{\star}$ \\
\hline High quantity regular & 4865 & $1.2(1.1 \text { to } 1.3)^{\star \star \star \star}$ & $1.2(1.1 \text { to } 1.4)^{\star \star \star \star}$ \\
\hline High quantity episodic & 76 & $1.2(0.8 \text { to } 2.0)^{\star}$ & $1.1(0.6 \text { to } 1.9)^{\star}$ \\
\hline \multicolumn{4}{|c|}{ Sleep disorder reported in 2001 ( $n=12$ 831): } \\
\hline No sleep disorder & 10432 & 1 & 1 \\
\hline Sleep disorder & 2061 & $1.2(1.1 \text { to } 1.3)^{\star \star \star \star}$ & $1.2(1.1 \text { to } 1.4)^{\star \star \star \star}$ \\
\hline Sleep disorder treated & 338 & $1.2(1.0 \text { to } 1.5)^{\star \star}$ & $1.2(0.9$ to 1.7$)$ \\
\hline \multicolumn{4}{|l|}{ Divorce in $2001(n=13$ 674): } \\
\hline No & 13508 & 1 & 1 \\
\hline Yes & 166 & $1.2(0.9 \text { to } 1.7)^{\star}$ & $0.9(0.6$ to 1.4$)$ \\
\hline \multicolumn{4}{|c|}{ Medical conditions treated in 2001 ( $n=13$ 674): } \\
\hline No & 12733 & 1 & 1 \\
\hline Dental or gum problems & 61 & $1.6(0.9 \text { to } 2.7)^{\star}$ & $1.6(0.8 \text { to } 3.1)^{\star}$ \\
\hline Cataract & 10 & - & - \\
\hline
\end{tabular}

\begin{tabular}{|c|c|c|c|}
\hline Variables & No & $\begin{array}{l}\text { Unadjusted odds ratio† } \\
\qquad(95 \% \mathrm{Cl})\end{array}$ & $\begin{array}{c}\text { Adjusted odds ratio } \neq \\
(95 \% \mathrm{Cl})\end{array}$ \\
\hline $\begin{array}{l}\text { Renal colic or kidney } \\
\text { stones }\end{array}$ & 24 & $1.2(0.5$ to 2.7$)$ & $1.2(0.4$ to 3.1$)$ \\
\hline Glaucoma & 106 & 1.0 (0.6 to 1.5$)$ & $0.9(0.5$ to 1.6$)$ \\
\hline Hiatus hernia & 316 & $1.2(1.0 \text { to } 1.6)^{\star *}$ & $1.4(1.0 \text { to } 1.8)^{\star \star}$ \\
\hline Gastric ulcers & 63 & $1.5(0.9 \text { to } 2.5)^{*}$ & $1.6(0.8 \text { to } 3.0)^{*}$ \\
\hline Diabetes & 361 & $0.8(0.6 \text { to } 1.0)^{*}$ & $0.9(0.7$ to 1.2$)$ \\
\hline \multicolumn{4}{|c|}{ Traffic ticket fixing $(n=13526)$} \\
\hline No & 9879 & 1 & 1 \\
\hline Yes & 3647 & $1.3(1.2 \text { to } 1.4)^{* * * *}$ & $1.2(1.1 \text { to } 1.3)^{* * *}$ \\
\hline \multicolumn{4}{|c|}{ Type A behaviour pattern scores $(n=11845)$ : } \\
\hline$\leq 48$ & 3114 & 1 & 1 \\
\hline 49 to 57 & 5372 & $1.1(1.0$ to 1.2$)$ & $0.9(0.8$ to 1.1$)$ \\
\hline$\geq 58$ & 3359 & $1.2(1.2 \text { to } 1.3)^{\star * *}$ & $0.9(0.8 \text { to } 1.0)^{*}$ \\
\hline
\end{tabular}

CES-D=Center for Epidemiologic Studies—depression scale.

${ }^{*} \mathrm{P} \leq 0.20$.

${ }^{* *} P \leq 0.05$.

$* * * P \leq 0.01$

$* * * * P \leq 0.001$.

†Odds ratio of reporting at least one episode of sleepy driving for each variable assessed separately and as an independent variable.

f0dds ratio of reporting at least one episode of sleepy driving adjusted for all variables. \&Low quantity drinkers defined as men reporting 1-13 (women 1-6) drinks over one week; high quantity drinkers reported 14-27 (men) and 7-20 (women) drinks over the same period; regular drinkers reported consuming alcohol on three or more days in the week; episodic drinkers reported drinking alcohol on less than three days a week.

driving while sleepy for two types of accidents: accidents due to sleepiness or worry and accidents in which the driver's responsibility was recognised by the insurance company.

\section{Discussion}

We found a robust association between self assessed driving while sleepy and the risk of serious road traffic accidents in the next three years; the risk increased with reported frequency of driving while sleepy. The association, as measured by adjusted rate ratios, was not modified by inclusion of a wide range of potential confounders. When we restricted the analysis to the subsample of participants who did not report any sleep disorders in 2001-3, the association was even stronger.

\section{Strengths and limitations}

Our results are consistent with previous findings from New Zealand, France, and the United States, ${ }^{3-5}$ and they support laboratory simulation studies suggesting that drivers are able to perceive that they are sleepy while driving. ${ }^{8}$ Our study is the only prospective study we are aware of; because participants were from a large cohort followed up on a regular basis, we were able to control carefully for a wide range of potential confounders, some of them updated each year. Additional analysis did not find any interaction effect with the nature of travel (commuting, professional, or private).

Both serious RTAs and driving while sleepy were self reported. Although self reported measures of risky driving behaviours have been found to have considerable validity in predicting risk of traffic accidents, ${ }^{16}$ they cannot account for all sleepy driving situations. This lack of accuracy is unlikely, however, to have biased our results-driving while sleepy does not constitute an offence against the Highway Code, and serious RTAs were recorded independently of risky driving behaviours. Furthermore, a recent study found that self reported sleepiness when driving was consistent with sleepiness as an independent model based on circadian and sleep factors. ${ }^{17}$ Finally, examination of the 260 complementary accident forms showed that participants who reported driving while sleepy at least once were more likely to report accidents due to sleepiness or worry 
Table 2 Rate ratios (95\% confidence intervals) of serious road traffic accidents in 2001-3 according to frequency of self reported driving while sleepy, determined by generalised linear Poisson regression models*

\begin{tabular}{|c|c|c|c|c|c|c|}
\hline Participants & Model 1 & Model 2 & Model 3 & Model 4 & Model 5 & Model 6 \\
\hline \multicolumn{7}{|l|}{ All participants } \\
\hline \multicolumn{7}{|c|}{ Self reported frequency of driving while sleepy in 2001: } \\
\hline Never $(n=8597)$ & 1 & 1 & 1 & 1 & 1 & 1 \\
\hline Once a month or more often $(n=160)$ & $3.0(1.5$ to 6.0$)$ & 3.0 (1.4 to 6.2$)$ & $2.9(1.4$ to 6.0$)$ & $2.8(1.3$ to 5.8$)$ & $2.9(1.4$ to 6.0$)$ & $2.9(1.3$ to 6.3$)$ \\
\hline No of observations used† & 37540 & 34854 & 32440 & 32440 & 32426 & 28362 \\
\hline \multicolumn{7}{|c|}{ Participants without sleep disorders reported or treated in 2001-3 } \\
\hline Never $(n=6679)$ & 1 & 1 & 1 & - & 1 & 1 \\
\hline A few times in the year $(n=3657)$ & 1.6 (1.2 to 2.1$)$ & 1.5 (1.2 to 2.0$)$ & 1.5 (1.1 to 2.0$)$ & - & 1.5 (1.1 to 2.0$)$ & 1.6 (1.2 to 2.2$)$ \\
\hline Once a month or more often $(n=96)$ & 4.5 (2.2 to 9.3$)$ & 4.7 (2.2 to 9.7$)$ & 4.7 (2.2 to 9.8$)$ & - & 4.9 (2.3 to 10.3$)$ & 4.8 (2.2 to 10.8$)$ \\
\hline No of observations used† & 29693 & 28581 & 26620 & - & 26612 & 23352 \\
\hline
\end{tabular}

* Model 1=unadjusted rate ratios; model 2=rate ratios adjusted for sex (male/female), age (covariate of three categories), occupational category (time dependent covariate of three categories: unskilled workers, skilled workers, managers), and driving mileage per year (time dependent covariate logarithmically transformed); model 3=model $2+$ alcohol consumption (five category, time dependent covariate describing quantity and frequency), maximum speed greater than $\pm 10 \%$ of legal limits in built-up areas (yes/no), on rural roads (yes/no), and on highways (yes/no), risky use of mobile phone (yes/no), vehicle categories (four categories), and traffic ticket fixing (yes/no); model 4=model 3 + sleep disorder (three category, time dependent covariate: no sleep disorder, sleep disorder, sleep disorder treated); model $5=$ model 4 + working overtime (never, occasionally, often/always), time constraints at work (never, occasionally, often/always), and working night shifts (never, on occasion, regularly); model 6=model $5+$ depressive symptoms in 2002 and use of drugs in 2001 (never, for anxiety, for depression, for other nervous disease, for sleep), medical conditions treated in 2001-3 (none, dental or gum problems, cataract, renal colic or kidney stones, glaucoma, hiatus hernia, gastric ulcers, diabetes); for analysis of participants without sleep disorders reported or treated in 2001-3, no adjustment was made for the sleep disorder variable in models 5 and 6 . tCumulative person years of observation during three year follow-up.

and accidents in which the responsibility of the participant was recognised by the insurance company.

We recorded driving while sleepy and serious RTAs in different time periods, assuming that driving while sleepy is a somewhat consistent behaviour over several years for a given driver. In 2004, we sent a second driving behaviour and road safety questionnaire to the participants in an attempt to assess changes in drivers' behaviour from the 2001 reports. Participants were asked the same questions as in 2001. Comparison of answers between 2001 and 2004 showed a fair stability in terms of driving while sleepy $(\kappa=0.47, \mathrm{P}=0.008)$. We also compared the risk of having at least one serious RTA in 2001 according to the frequency of driving while sleepy reported over the same period (data not shown). We found a similar trend, but the statistical power was low.

For comparative purposes, we estimated the population attributable risk for sleepy driving as $19 \%$, a figure consistent with data from a study in New Zealand (19\%). ${ }^{3}$ Published estimates of the proportion of car crashes attributable to the driver's sleepiness range widely, from about $3 \%$ to $33 \% .^{3-5} 7$ Our study sample, despite its large size, was not representative of French drivers as a whole. The participants had various jobs and were from different socioeconomic groups throughout France, but all were middle aged drivers.

The association between self assessed driving while sleepy and the risk of serious RTAs was stronger when we restricted the analysis to a subsample of participants who did not report any sleep disorders in 2001-3. Although people with sleep disorders were more likely to report driving while sleepy (table 1), the association measure between self reported sleep disorders and the risk of serious RTAs seemed to be lower. This suggests that drivers with previous sleep disorders may adopt self regulatory behaviours.

\section{Implications}

Our prospective data clearly identified driving while sleepy unrelated to any medical condition as a significant independent factor contributing to serious RTAs, with important consequences for public safety because of the high proportion of drivers concerned. ${ }^{18}$ Our results suggest that drivers are aware that they are sleepy when driving but do not act accordingly. ${ }^{19}$ This has already been noted by Reyner and Horne, who found that perception of sleepiness does not result in cessation of driving in laboratory simulations. ${ }^{8}$ Drivers may either underestimate the impact of sleepiness on their driving performance or overestimate their capacity to fight sleepiness. ${ }^{5}$

As self assessment of sleepiness while driving seems possible, the role of policing should consist in the development and implementation of national campaigns to raise the awareness of all road users and to inform them how to avoid driving while sleepy through promotion of "sleep hygiene" or how to deal with sleepiness. ${ }^{20}$ The only long lasting solution, however, is to stop driving and sleep or to let someone else drive. ${ }^{19-21}$ Prevention programmes should also include building or improving rest areas and installing shoulder rumble strips. In addition, legislative or regulatory initiatives should also be discussed, ${ }^{22}$ even if appropriate tools to measure drivers' sleepiness are still to be developed. Finally, development and evaluation of in-vehicle systems that can detect a sleepy driver should also be promoted.

We thank everyone who supported this work and in particular the staff of unit 687 of INSERM. We especially thank Sébastien Bonenfant, Nadine Kaniewsky, and Nathalie Lopes for their valuable help throughout the study and Marcel Goldberg, Jean-François Chastang, and Pierre Philip for advice and support.

Contributors: HN analysed and interpreted data and wrote the report. EL conceived the study and contributed to the analysis and interpretation of data and to the preparation of the manuscript. AG was involved in analysing and interpreting data. MC, SL, and MZ contributed to study design and interpretation of data. All authors contributed to the final version of the report. EL is the guarantor.

\section{What is already known on this topic}

Retrospective studies suggest that sleepiness in drivers is an important factor contributing to the burden of traffic related morbidity and mortality

What this study adds

Self assessed driving while sleepy is a powerful predictor of serious road traffic accidents

This suggests that drivers are able to accurately assess sleepiness while driving but do not act accordingly 
Funding: Electricité de France-Gaz de France and Fondation MAIF. The funding bodies had no inputs to the study design; the collection, analysis, and interpretation of data; the writing of the report; or the decision to submit the paper for publication.

Competing interests: None declared.

Ethical approval: The study protocol was approved by the French data protection authority (Commission Nationale Informatique et Liberté).

1 Philip P, Sagaspe P, Moore N, Taillard J, Charles A, Guilleminault C, et al. Fatigue, sleep restriction and driving performance. Accid Anal Prev 2005;37:473-8.

2 Connor J, Whitlock G, Norton R, Jackson R. The role of driver sleepiness in car crashes: a systematic review of epidemiological studies. Accid Anal Prev 2001;33:31-41.

3 Connor J, Norton R, Ameratunga S, Robinson E, Civil I, Dunn R, et al. Driver sleepiness and risk of serious injury to car occupants: population based case control study. BMJ and risk of serious injury to car occupants: population based case control study. BMJ 2002;324:1125.

4 Philip P, Vervialle F, Le Breton P, Horne JA. Fatigue, alcohol, and serious road traffic crashes in France: factorial study of national data. BMJ 2001;322:829-30.

5 Lyznicki JM, Doege TC, Davis RM, Williams MA. Sleepiness, driving, and motor vehicle crashes. JAMA 1998;279:1908-13.

6 Knipling RR, Wang J-S. Crashes and fatalities related to driver drowsiness/fatigue. Washington, DC: Office of Crash Avoidance Research, US Dept of Transportation, 1994.

7 Pierce RJ. Driver sleepiness: occupational screening and the physician's role. Aust N ZJ Med 1999;29:658-61.

8 Reyner LA, Horne JA. Falling asleep whilst driving: are drivers aware of prior sleepiness? Int J Legal Med 1998;111:120-3.

9 National Sleep Foundation. 2005 sleep in America poll: summary of findings. Washington, DC: National Sleep Foundation, 2005.

10 TNS-Sofres. Les Français et la somnolence: résultats d'étude. La Tronche: Institut du sommeil et de la vigilance, 2004.

11 Lagarde E, Chiron M, Lafont S. Traffic ticket fixing and driving behaviours in a large French working population.J Epidemiol Community Health 2004;58:562-8.

12 Nabi H, Consoli SM, Chastang JF, Chiron M, Lafont S, Lagarde E. Type A behavior pattern, risky driving behaviors, and serious road traffic accidents: a prospective study of the GAZEL cohort. Am J Epidemiol 2005;161:864-70.

13 Lagarde E, Chastang JF, Lafont S, Coeuret-Pellicer M, Chiron M. Pain and pain treatment were associated with traffic accidents involvement in a cohort of middle-aged workers. J Clin Epidemiol 2005;58:524-31.
14 McCullagh P, Nelder JA. Generalized linear models. London: Chapman and Hall, 1989. 15 Rothman KJ, Greenland S. Modern epidemiology. 2nd ed. Philadelphia: LippincottRaven, 1998.

16 Fergusson D, Swain-Campbell N, Horwood J. Risky driving behaviour in young people: prevalence, personal characteristics and traffic accidents. Aust N Z J Public Health

17 Smith S, Carrington M, Trinder J. Subjective and predicted sleepiness while driving in young adults. Accid Anal Prev 2005;37:1066-73.

18 Drobnich D. A National Sleep Foundation's conference summary: the national summit to prevent drowsy driving and a new call to action. Ind Health 2005;43:197-200.

19 Dalziel JR, Job RF. Motor vehicle accidents, fatigue and optimism bias in taxi drivers. Accid Anal Prev 1997;29:489-94

20 MacLean AW, Davies DR, Thiele K. The hazards and prevention of driving while sleepy. Sleep Med Rev 2003;7:507-21.

21 Horne JA. Sleep-related vehicle accidents: some guidelines for road safety policies. Transportation Research-Part F 2001;4:63-74.

22 Rosen IM. Driving while sleepy should be a criminal offense. J Clin Sleep Med 2005; 1:337-4.

(Accepted 14 April 2006)

doi 10.1136/bmj.38863.638194.AE

Institut National de la Santé et de la Recherche Médicale, U687-IFR69, Saint-Maurice, F-94415 France

Hermann Nabi PhD research student

Alice Guéguen statistician

Marie Zins physician epidemiologist

Emmanuel Lagarde senior researcher

Institut National de Recherche sur les Transports et leur Sécurité, UMRESTTE, F-69675 Bron, France

Mireille Chiron senior researcher

Sylviane Lafont statistician

Correspondence to: E Lagarde, Equipe Avenir "Santé et Insécurité Routière,"

INSERM Unité 593, Université Victor Segalen Bordeaux 2, Case 11, 146 rue Léo

Saignat, 33076 Bordeaux Cedex, France emmanuel.lagarde@isped.u-bordeaux2.fr 